NBER WORKING PAPER SERIES

\title{
SOCIAL SECURITY PRIVATIZATION WITH ELASTIC LABOR SUPPLY AND SECOND-BEST TAXES
}

\author{
Kent Smetters \\ Working Paper 11101 \\ http://www.nber.org/papers/w11101 \\ NATIONAL BUREAU OF ECONOMIC RESEARCH \\ 1050 Massachusetts Avenue \\ Cambridge, MA 02138 \\ February 2005
}

The views expressed herein are those of the author(s) and do not necessarily reflect the views of the National Bureau of Economic Research.

(C) 2005 by Kent Smetters. All rights reserved. Short sections of text, not to exceed two paragraphs, may be quoted without explicit permission provided that full credit, including $\odot$ notice, is given to the source. 
Social Security Privatization with Elastic Labor Supply and Second-Best Taxes

Kent Smetters

NBER Working Paper No. 11101

February 2005

JEL No. H0, H2

\begin{abstract}
$\underline{\text { ABSTRACT }}$
This paper shows that many common methods of privatizing social security fail to reduce labor market distortions when taxes are second best, challenging a key reason to privatize. Ironically, providing "transition relief" to workers alive at the time of the reform, in an effort to protect their previous contributions, undercuts potential efficiency gains. Chile's reform -- the first major privatization that also served as a model for other countries -- actually increased labor market distortions. It is then shown that privatization with limited transition relief can reduce labor market distortions and produce gains to current and future generations without hurting initial retirees, i.e., a Pareto gain, even with second-best taxes.

Kent Smetters

The Wharton School

3302 Steinberg Hall - Dietrich Hall

3620 Locust Walk

Philadelphia, PA 19104-6302

and NBER

smetters@wharton.upenn.edu
\end{abstract}




\title{
Social Security Privatization with Elastic LABOR SUPPLY AND SECOND-BEST TAXES
}

By Kent Smetters ${ }^{1}$

January 1, 2005

\begin{abstract}
This paper shows that many common methods of privatizing social security fail to reduce labor market distortions when taxes are second best, challenging a key reason to privatize. Ironically, providing "transition relief" to workers alive at the time of the reform, in an effort to protect their previous contributions, undercuts potential efficiency gains. Chile's reform -- the first major privatization that also served as a model for other countries -- actually increased labor market distortions. It is then shown that privatization with limited transition relief can reduce labor market distortions and produce gains to current and future generations without hurting initial retirees, i.e., a Pareto gain, even with second-best taxes.
\end{abstract}

\section{INTRODUCTION}

While privatizing a pay-as-you-go social security system could increase saving, it involves a zero-sum reallocation of resources between generations inside the standard neoclassical model with inelastic labor supply. ${ }^{2}$ Intuitively, social security does not distort the relative price of consumption between calendar dates -- the only margin for distortions in this setting. Any gains to future generations, therefore, must be offset in present value with losses to at least one earlier generation. Discussions about social security reform in this context, therefore, are limited to normative debates about different inter-generational resource distributions within the set of Pareto-efficient allocations.

\footnotetext{
${ }^{1}$ The Wharton School and NBER (smetters@ wharton.upenn.edu). This research was supported by the U.S. Social Security Administration through a grant to the Michigan Retirement Research Consortium as part of the SSA Retirement Research Consortium. The opinions and conclusions expressed are solely those of the author and do not represent the opinions or policy of SSA or any agency of the Federal Government. I benefited from several discussions with Alan Auerbach while visiting the Robert D. Burch Center at the Department of Economics at Berkeley in the summer of 2003. I also received helpful comments from David Cutler, Martin Feldstein, Roger Gordon, Caroline Hoxby and other seminar participants at Harvard.

${ }^{2}$ See Breyer (1989); Feldstein (1995); Geanakoplos, Mitchell and Zeldes (1998); Murphy and Welch (1998); Mariger (1999); Shiller (1999). An exception is if privatization can exploit a wedge between the social and private marginal cost of capital in the presence of capital income taxes (Feldstein and Liebman, 2002). Since these gains could also be achieved by simply switching to a labor income tax (i.e., without privatization), it is also interesting to know if a Pareto improvement were possible with only labor taxes.
} 
When labor supply is elastic, social security payroll taxes distort labor supply choices relative to first-best taxation. This distortion stems from the pay-as-you-go financing itself. If the economy is dynamic efficiency (i.e., does not grow at a rate faster than interest), workers born into a mature pay-as-you-go social security system receive a rate of return on their contributions from social security that is lower than the return that they could have earned in the capital market. This lower yield produces an effective net tax rate on earnings that, although less than the statutory tax rate, is positive and potentially large, especially for younger workers who face the compound effects of foregone interest over their remaining work life (Feldstein and Samwick, 1992).

Privatizing social security when labor supply is elastic could increase economic efficiency if the government had access to first-best taxes (Breyer and Straub, 1993; Feldstein, 1996; Feldstein and Liebman, 2002). In other words, existing pay-as-you-go social security systems create excess burden in the traditional sense of Hicks (1943, 1944-5) and Harberger (1974). However, if the government had access to first-best taxes, then these efficiency gains could be achieved even without privatization.

It is also interesting to know, therefore, if privatization could produce efficiency gains if the government's policy instruments are restricted to second-best labor income taxes. As Brunner (1996) demonstrates, such a gain is not possible in a standard twoperiod overlapping-generations model where agents work for the first period and retire the second period. Allowing workers to divert their pay-as-you-go payroll taxes to private accounts would require levying a new labor income tax on workers in order to continue to pay the social security benefits of those retired at the time of this reform. 
This reform would simply substitute one distorting tax for another, producing no gains. ${ }^{3}$ This result, therefore, seriously challenges a key rational for privatization.

The current paper demonstrates that, in a model with three or more periods, privatization can produce efficiency gains in the presence of elastic labor supply even when only second-best labor income taxes are available. With multiple periods, a household's accrued benefit (which is observable by the government) becomes a source for an efficient implicit lump sum tax that can be used to replace the future revenue that would have been collected using a distorting labor income tax. Equivalently, this implicit wealth levy can afford participants a higher return on their future contributions, thereby reducing the effective tax rate on their labor supply.

To understand this result intuitively, consider the following experiment. Suppose that households work for two periods and retire the third period. The government suddenly decides that it no longer recognizes the Social Security benefits that the secondperiod period workers accrued during their first period of life. In exchange for this implicit wealth levy, however, the government gives these workers the capital market rate of return on a portion of their second-period contributions (i.e., privatizes a portion of their second-period contributions). The portion of second-period contributions invested in the capital market is set to produce a revenue loss equal in present value to the implicit wealth levy at the pre-reform level of labor supply.

Workers are clearly better off under this experiment because they are fully compensated for their losses in present value but they now face better labor supply incentives. The government's inter-temporal budget constraint is also improved because labor supply unambiguously increases, which helps future generations by lowering taxes.

\footnotetext{
${ }^{3}$ Brunner's equivalent approach shows that lump-sum taxes do not respect intra-generational heterogeneity.
} 
To capture these gains, however, the privatization experiment must be designed correctly. This paper shows that several common privatization plans fail to produce efficiency gains since they provide "transition relief" to workers alive at the time of the reform in order to protect their previous contributions. This outcome is somewhat ironic since the relief is typically given in an attempt to avoid generating losers. It is then shown that a privatization with limited transition relief can reduce labor market distortions and produce gains to current and future generations without hurting initial retirees (i.e., a Pareto gain) even if the government's taxes are second best.

Section 2 outlines the pre-reform economy with a pay-as-you-go social security system. Section 3 shows how several standard privatization plans fail to produce efficiency gains. Section 4 shows how privatization with limited transition relief can produce efficiency gains while respecting worker heterogeneity. Section 5 concludes.

\section{THE PRE-REFoRM ECONOMY}

This section describes the economy before social security is reformed.

\subsection{Demographics and Factor Prices}

There are $N_{t}$ first-period agents alive at time $t$. Population grows at time $t$ grows at rate $n_{t} \equiv N_{t} / N_{t-1}$. The total wage base time $t$ grows at a gross rate $G_{t} \equiv\left(1+g_{t}\right) \equiv$ $\left(1+n_{t}\right)(1+x)$, where $x$ is the exogenous and constant rate of technological change between time periods. We assume that the population is stationary and so we drop the time subscripts for $N$ and $G$ in the subsequent discussion. The gross rate of return to riskless capital is $R=(1+r)$, where $r$ is the net rate of return. The wage rate at time $t$ is $w_{t}$, 
which grows at rate $x$, i.e., $w_{t+1}=(1+x) w_{t}$. These factor prices are stationary (or, in the case of wages, trend stationary) as in a small open economy or with linear technology.

\subsection{Households}

Agent $j$ is born at time $t$ and lives for three periods. The agent has exogenous levels of productivity of $\alpha_{1}^{j}$ and $\alpha_{2}^{j}$ in the first and second periods, respectively, which are indexed by $j$ to allow for heterogeneity. Productivity in the third period is zero.

Lifetime utility is given by $\sum_{k=1}^{3} \beta^{k} u\left(c_{k, t}^{j}, 1-l_{k, t}^{j}\right)$, where $c_{k, t}^{j}$ is the level of consumption at age $k$ and $l_{k, t}^{j}$ is the level of labor supply where the total time endowment each period is normalized to unity. The function $u($,$) is increasing and concave in both$ arguments. Our focus on "compensated" reforms below does not require restrictions on the cross-partial derivatives of $u($,$) . Lifetime utility is maximized subject to:$

$$
\begin{aligned}
& c_{1, t}^{j}+a_{1, t}^{j}=\alpha_{1}^{j} w_{t} l_{1, t}^{j}(1-\tau) \\
& c_{2, t+1}^{j}+a_{2, t+1}^{j}=\alpha_{2}^{j} w_{t+1} l_{2, t+1}^{j}(1-\tau)+R a_{1, t}^{j} \\
& c_{3, t+2}^{j}=R a_{2, t+1}^{j}+b_{t+2}^{j}
\end{aligned}
$$

where $b$ is the pay-as-you-go social security benefit received in the third period financed on a pay-as-you-go basis with a proportional tax, $\tau$, on labor earnings. ${ }^{4}$ By construction, this tax is second-best since, as in the original optimal tax problem of Mirrlees, the government can observe labor earnings but not productivity (or hours worked).

\footnotetext{
${ }^{4}$ The rest of the government's operations outside of social security are ignored in this paper for simplicity. Including them would not impact the results herein. Indeed, if capital income taxes were also in place, additional gains from privatization could be obtained, as shown in Feldstein and Liebman (2002).
} 


\subsection{Social Security}

Over 150 countries have defined-benefit social security systems that are mostly pay-as-you-go financed. In most cases, benefits are proportional to the average of past earnings; in a few countries like the United States, benefits paid relative to previous earnings are decreasing in the value of average past earnings, although some of this redistribution might be offset by differences in mortality and spousal qualifications. ${ }^{5}$

\subsubsection{Proportional Benefits}

We initially, therefore, focus on a social security system where benefits are proportional to previous contributions. In this system, every agent gets the same gross "internal" rate of return to their social security contributions. In a mature and stationary pay-as-you-go system, this internal rate of return is equal to the growth rate of the wage tax base, that is, $G$. Agent $j$ 's social security benefit in the third year, therefore, equals ${ }^{6}$

$$
b_{t+2}^{j}=G^{2} \tau \alpha_{1}^{j} w_{t} l_{1, t}^{j}+G \tau \alpha_{2}^{j} w_{t+1} l_{2, t+1}^{j}
$$

\subsubsection{Age-Specific Marginal Net Tax Rates}

The net social security tax paid by agent $j$ at a given age equals the value of taxes paid at that age less the present value of future benefits received from that tax. For agents born into a mature pay-as-you-g social security system, these taxes are as follows:

$$
\begin{aligned}
& \tilde{T}_{1, t}^{j} \equiv \tau \alpha_{1}^{j} w_{t} l_{1, t}^{j}-(G / R)^{2} \tau \alpha_{1}^{j} w_{t} l_{1, t}^{j}=\left[1-(G / R)^{2}\right] \tau \alpha_{1}^{j} w_{t} l_{1, t}^{j} \\
& \tilde{T}_{2, t+1}^{j} \equiv \tau \alpha_{2}^{j} w_{t+1} l_{2, t+1}^{j}-(G / R) \tau \alpha_{2}^{j} w_{t+1} l_{2, t+1}^{j}=[1-(G / R)] \tau \alpha_{2}^{j} w_{t+1} l_{2, t+1}^{j} \\
& \tilde{T}_{3, t+2}^{j}=0
\end{aligned}
$$

\footnotetext{
${ }^{5}$ See, for example, Gustman and Steinmeier (2001).

${ }^{6}$ I.e., In a stationary economy with a single type of household (to reduce notation), equation (4) can be rewritten as the standard pay-as-you-go constraint, $N_{t} b_{t+2}=N_{t+2} \tau \alpha_{1} w_{t+2} l_{1, t+2}+N_{t+1} \tau \alpha_{2} w_{t+2} l_{2, t+2}$.
} 
In other words, the budget constraints (1) - (4) could be rewritten as

(1') $\quad c_{1, t}^{j}+a_{1, t}^{j}=\alpha_{1}^{j} w_{t} l_{1, t}^{j}-\tilde{T}_{1, t}^{j}$

(2') $\quad c_{2, t+1}^{j}+a_{2, t+1}^{j}=\alpha_{2}^{j} w_{t+1} l_{2, t+1}^{j}+R a_{1, t}^{j}-\tilde{T}_{2, t+1}^{j}$

(3') $\quad c_{3, t+2}^{j}=R a_{2, t+1}^{j}$

Agent $j$ is indifferent between constraints (1) - (4) and constraints (1') - (3'). We will use this fact in some of the results shown in Section 3.

The implicit effective marginal net tax rates on wages indicate how much the net taxes increase with wage income earned at a particular age in life:

$$
\begin{aligned}
& \tilde{\tau}_{1, t}^{j} \equiv \partial \tilde{T}_{1, t}^{j} / \partial\left(\alpha_{1}^{j} w_{t} l_{1, t}^{j}\right)=\left[1-(G / R)^{2}\right] \tau \\
& \tilde{\tau}_{2, t+1}^{j} \equiv \partial \tilde{T}_{2, t+1}^{j} / \partial\left(\alpha_{2}^{j} w_{t+1} l_{2, t+1}^{j}\right)=[1-(G / R)] \tau . \\
& \tilde{\tau}_{3, t+2}^{j} \equiv 0
\end{aligned}
$$

We focus on a dynamically efficient economy, which implies $R>G ;^{7}$ otherwise, expanding pay-as-you-go financing would be Pareto improving (Samuelson, 1958). The marginal tax rates faced by agent $j$ at ages 1 and 2, therefore, are positive but below the statutory tax rate, $\tau$. Also notice that $\tilde{\tau}_{2, t+1}^{j}<\tilde{\tau}_{1, t}^{j}$, i.e., the net marginal tax rate decreases in the agent $j$ 's age as the "compound effect" of the $(G / R)$ wedge is reduced.

\footnotetext{
${ }^{7}$ See Abel, Mankiw, Summers and Zeckhauser (1989) for evidence of dynamic efficiency. With a capital income tax, however, it is possible that $R>G$ while the after-tax return to capital is equal to or less than $G$. Still, social security distorts labor supply relative to first-best taxes where workers could save at rate $R$.
} 


\subsection{Government's Budget Constraint}

Let $\Gamma_{t}^{j} \equiv \tilde{T}_{1, t}^{j}+(1 / R) \tilde{T}_{2, t+1}^{j}$, the present value of the net lifetime Social Security taxes paid by the $j$ agent born at time $t$. The aggregate net lifetime taxes paid by people born at time $t$ is $N_{t} \int_{j \in E} \Gamma_{t}^{j} \mathrm{~d} X(j)$. The government's inter-temporal budget constraint requires that the present value of net lifetime transfers across all generations sum to zero,

(11) $\quad \sum_{t=-2}^{\infty} \frac{N_{t}}{R^{t}} \int_{j \in E} \Gamma_{t}^{j} \mathrm{~d} X(j)=0$

where Social Security is assumed to have begun at time $0 .(X$ is a stationary cumulative measure of households corresponding to the set, $E$, of potential age-productivity vectors.) To reduce notation and without much loss in generality, we ignore the other types of (non-social security) goods and services that are typically provided by the government.

Constraint (11) is quite general and incorporates both pay-as-you-go and funded social security systems. It can be shown that constraint (11) is implied by the morerestrictive pay-as-you-go constraint (4) when $R>G$ (but the converse is not true).

Under the pay-as-you-go constraint (4), equation (11) has the interpretation that the windfalls to retirees and older workers alive at time 0 are financed by the sum of net taxes paid by future generations in present value. In particular, rewrite equation (11) as

$$
\overbrace{-N_{-2} \int_{j \in E} R^{2} \Gamma_{-2}^{j} \mathrm{~d} X(j)}^{\text {Windfall to Generation -2 }} \overbrace{-N_{-1} \int_{j \in E} R \Gamma_{-1}^{j} \mathrm{~d} X(j)}^{\text {Windfall to Generation - } 1}=\overbrace{\sum_{t=0}^{\infty} \frac{N_{t}}{R^{t}} \int_{j \in E} \Gamma_{t}^{j} \mathrm{~d} X(j)}^{\text {Net Taxes Paid by Generations } t \geq 0},
$$

where generation "-2" represents the third-period agents (retirees) alive when the social security system began at time 0 , and generation "- 1 " represents the second-period agents (older workers) alive at time 0 . The present value (as of time 0 ) of the windfall to agent $j$ 
of generation -2 is $-R^{2} \Gamma_{-2}^{j}=-R^{2} \tilde{T}_{1,-2}^{j}-R \tilde{T}_{2,-1}^{j}=G^{2} \tau \alpha_{1}^{j} w_{-2} l_{1,-2}^{j}+G \tau \alpha_{2}^{j} w_{-1} l_{2,-1}^{j}$, which by equation (4) is equal to $b_{0}^{j} \cdot{ }^{8}$ The present value windfall to agent $j$ of generation -1 , though, is more complicated. Like generation -2 , generation -1 receives benefits based on their entire lifetime of wages. But, unlike generation -2 , generation -1 pays taxes during their second period. Hence, $-R \Gamma_{-1}^{j}=-R \tilde{T}_{1,-1}^{j}-\tilde{T}_{2,0}^{j}=\left(\frac{G^{2} \tau \alpha_{1}^{j} w_{-1} l_{1,-1}^{j}}{R}\right)-\tau \alpha_{2}^{j} w_{0} l_{2,0}^{j}$ $+(G / R) \tau \alpha_{2}^{j} w_{0} l_{2,0}^{j}=\frac{b_{1}^{j}}{R}-\tau \alpha_{2}^{j} w_{0} l_{2,0}^{j}$. We can, therefore, rewrite (12) as

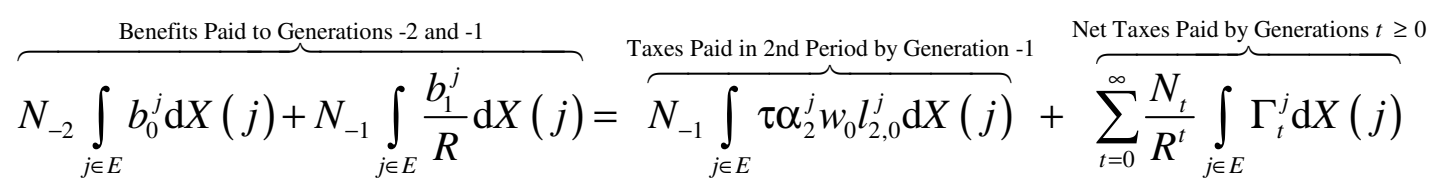

\subsection{1. "Actuarially-Fair" Reforms}

Since this paper focuses on efficiency gains, we consider "actuarially-fair" reforms, that is, reforms that do not change the present value of net lifetime taxes of any household at pre-reform levels of labor income, i.e., reforms for which the value of $\Gamma_{t}^{j}$ remains unchanged at pre-reform levels of labor supply.

It is important to distinguish between fair reforms and a fair initial social security system. When $R>G$, a pay-as-you-go social security system is actuarially unfair to generations born into it since they must pay for the windfall gain to previous generations who received more in benefits in present value than they paid in taxes. However, the reforms we consider herein are actuarially fair when judge against the market rate, $R$, in that they do not change the resource allocation either inter- or intra-generationally.

\footnotetext{
${ }^{8}$ Recall that equations (5) and (6) apply to agents who are born into a mature pay-as-you-go social security system. For generation $-2, \tilde{T}_{1,-2}^{j} \equiv-(G / R)^{2} \tau \alpha_{1}^{j} w_{-2} l_{1,-2}^{j}$ and $\tilde{T}_{2,-1}^{j} \equiv-(G / R) \tau \alpha_{2}^{j} w_{-1} l_{2,-1}^{j}$.
} 
The focus on actuarially-fair reforms does not constrain the analysis in the current deterministic-wage setting because the efficiency gains we derive herein come from reducing the distortions of those alive at the time of the reform, not from reducing distortions (or completing missing markets) either within or between generations. In a model with uninsurable idiosyncratic wage uncertainty but no aggregate risk, it may be possible to create a Pareto improving reform that does not change the inter-generational allocation of resources but improves intra-generational risk sharing. ${ }^{9}$ In a model with aggregate uncertainty and incomplete trading markets between generations, statecontingent reallocations of resources across generations might improve risk sharing. ${ }^{10}$ The deterministic framework herein rules out these additional potential margins. ${ }^{11}$

\section{Two Common Privatization Proposals}

This section shows that two common proposals to privatize social security fail to produce efficiency gains; Chile's privatization, in fact, reduced efficiency.

\subsection{The "Carve Out"}

One way of introducing personal accounts is to "carve out" a portion of an agent's social security payroll tax and to deposit the money into a personal account. Since an agent pays less money into the traditional defined-benefit social security system, her future social security benefit is reduced by an equal amount in present value. Carve out

\footnotetext{
${ }^{9}$ Mathematically, $\int_{j \in E} \Gamma_{t}^{j} \mathrm{~d} X(j)$ is unchanged for all $t$ but the values of $\Gamma_{t}^{j}$ could change.

${ }^{10}$ See, for example, Bohn (2003), Krueger and Kubler (2002) and Diamond and Geanakoplos (2003).

${ }^{11}$ In so doing, however, we also ignore the possible risk sharing advantages of the pre-reform social security system relative to a privatized system. Nishiyama and Smetters (2004) consider these competing effects using a large-scale lifecycle simulation model. The current paper focuses on demonstrating the potential source of efficiency gains from privatization, which is not widely understood.
} 
plans are the most common type of reforms being discussed for the U.S. system, including by the recent 2001 President's Commission to Strengthen Social Security.

Suppose that a portion $\pi$ of the payroll tax, $\tau$, is carved out and placed into a personal account while the remaining $(1-\pi)$ of $\tau$ continues to be paid to social security. Dropping time subscripts to reduce clutter, the new budget constraints are

$$
\begin{aligned}
& c_{1}^{j}+a_{1}^{j}=\alpha_{1}^{j} w l_{1}^{j}(1-\tau \pi-\tau[1-\pi])=\alpha_{1}^{j} w l_{1}^{j}(1-\tau) \\
& c_{2}^{j}+a_{2}^{j}=\alpha_{2}^{j}(1+x) w l_{2}^{j}(1-\tau \pi-\tau[1-\pi])+R a_{1}^{j}=\alpha_{2}^{j}(1+x) w l_{2}^{j}(1-\tau)+R a_{1}^{j} \\
& c_{3}^{j}=R a_{2}^{j}+b^{j}
\end{aligned}
$$

where $b^{j}$ is now the third-period assets that are in the new carve-out personal account plus the reduced benefit that is received from the social security system:

$$
\begin{aligned}
b^{j}= & \overbrace{\left[G^{2} \alpha_{1}^{j} w l_{1}^{j} \tau-R^{2} \alpha_{1}^{j} w l_{1}^{j} \tau \pi\right]}^{\text {1st-Period Accrued Benefit less Reduction }}+\overbrace{\left[G \alpha_{2}^{j}(1+x) w l_{2}^{j} \tau-R \alpha_{2}^{j}(1+x) w l_{2}^{j} \tau \pi\right]}^{\text {2nd-Period Accrued Benefit less Reduction }} \\
& +\overbrace{\left[R^{2} \alpha_{1}^{j} w l_{1}^{j} \tau \pi+R \alpha_{2}^{j}(1+x) w l_{2}^{j} \tau \pi\right]}^{\text {Assets in new Carve-Out Personal Account }} \\
= & G^{2} \alpha_{1}^{j} w l_{1}^{j} \tau+G \alpha_{2}^{j}(1+x) w l_{2}^{j} \tau
\end{aligned}
$$

Notice that after the algebraic reductions shown in equations (13) - (16), these constraints are identical to the original budget constraints (1) - (4). As a result, the marginal net tax rates are unaffected by the introduction of an actuarially-fair carve out. In other words, this reform is economically neutral, thereby proving the following result:

Proposition 1. The actuarially-fair "carve out," where a household's future social security benefit is reduced equal in present value to the payroll taxes they divert to their private account, is neutral. In particular, labor supply incentives are not improved. 
Intuitively, on one hand, lowering the tax rate paid into the traditional pay-as-yougo social security system reduces marginal tax rates across all ages. On the other hand, the concomitant benefit reduction has the effect of increasing the marginal tax rate on contributions, raising the effective marginal tax rates back to their pre-reform levels.

\subsection{The "Shutdown" with Recognition Bonds}

Another reform would "shut down" the social security system altogether and avoid harming workers in the transition by depositing recognition bonds into their personal accounts; retirees at the time of the reform continue to receive the same benefits as under social security. The recognition bonds plus the benefits paid to the initial retirees are financed in present value by a set of new labor income taxes described below.

\subsubsection{Second-Period Workers at the Time of the Reform}

Consider middle-age (second-period) workers alive at the start of the reform who accrued benefits under social security. Their new budget constraints are as follows:

$$
\begin{aligned}
& c_{1}^{j}+a_{1}^{j}=\alpha_{1}^{j} w l_{1}^{j}(1-\tau) \\
& c_{2}^{j}+a_{2}^{j}=\alpha_{2}^{j}(1+x) w l_{2}^{j}+R a_{1}^{j}+B_{2}^{j}-\tilde{T}_{2}^{j} \\
& c_{3}^{j}=R a_{2}^{j},
\end{aligned}
$$

where the budget constraint, (17), during the first period of life under social security in included for completeness. The recognition bond, $B_{2}^{j}$, is equal to accrued liability,

$$
B_{2}^{j}=\left(\frac{\tau \alpha_{1}^{j} w l_{1}^{j} G^{2}}{R}\right),
$$

which is calculated by grossing up previous contributions by the internal rate of return that agent $j$ would have received under social security during the third year of life and then discounting it back in time to the second period of life. 
The pure tax $\tilde{T}_{2}^{j}$, shown in equation (18), which is levied after the reform takes place in the second period of life, is defined in equation (6). It represents this generation's share of taxes that are needed to support the benefits paid to initial retirees.

Substituting the values of $B_{2}^{j}$ and $\tilde{T}_{2}^{j}$ into equation (18) leaves the following set of budget constraints

(17') $\quad c_{1}^{j}+a_{1}^{j}=\alpha_{1}^{j} w l_{1}^{j}(1-\tau)$

(18') $\quad c_{2}^{j}+a_{2}^{j}=\alpha_{2}^{j}(1+x) w l_{2}^{j}(1-\tau)+R a_{1}^{j}+\left[\frac{\tau \alpha_{1}^{j} w l_{1}^{j} G^{2}+\tau \alpha_{2}^{j} w(1+x) l_{2}^{j} G}{R}\right]$ (19') $\quad c_{3}^{j}=R a_{2}^{j}$,

Notice that the value in the [ ] brackets is equal to the present value (as of the second period) of the social security benefit shown in equation (4). Notice that this set of budget constraints is identical to the original budget constraints (1) - (4), thereby leading to no reductions in labor supply distortions.

\subsubsection{Young and Future Generations at the Time of the Reform}

After the shutdown, young and future generations do not pay social security taxes or receive any social security benefits. They also do not receive any recognition bonds since they have not accrued any benefits by the time of the reform. However, they must help finance the social security benefits that were paid to the initial retirees at the time of the privatization plus the value of recognition bonds.

Given the revenue from the pure labor tax, $\tilde{T}_{2}^{j}$, that is paid by second-period workers alive at the time of the privatization (shown above), the remaining unfunded liabilities can be financed exactly in present value if all future workers pay a pure labor 
tax equal to $\tilde{T}_{1}^{j}$ during the first period and $\tilde{T}_{2}^{j}$ during the second period, as shown in budget constraints $\left(1^{\prime}\right)-\left(3^{\prime}\right) .^{12}$ The equivalence of these budget constraints with constraints (1) - (4) implies that young workers and future workers are indifferent to the shutdown as well. We have, therefore, proven the following result:

Proposition 2. The actuarially-fair "shut down," where social security is eliminated (except for current retirees) and recognition bonds are given to workers in lieu of their accrued benefits, is neutral. In particular, labor supply incentives are not improved.

\subsection{Remark on Rational Expectations}

Propositions 1 and 2 assume that people know the marginal tax-benefit linkage under the pre-reform system, i.e., they have rational expectations. This calculation is difficult in practice, and so these two privatizations could increase efficiency indirectly by distinguishing between the effective (pure) tax rates and the statutory tax rate. This type of gain has been explored in Auerbach and Kotlikoff (1987, Chapter 10). The current paper instead explores whether gains are possible even with rational expectations.

\subsection{Chile's Reform}

When Chile privatized its social security system during the early 1980s, it used a slightly different calculation of the recognition bonds relative to the actuarially-fair method that was shown above. In particular, the Chilean government simply grossed up previous contributions by the market interest rate, $R$, instead of by the internal rate of

\footnotetext{
${ }^{12}$ In practice, the government would presumably issue new debt to finance the benefits of the initial retirees. The new pure taxes for middle-aged and future workers shown in the text can then be interpreted as the interest payments on the rollover of this new debt plus recognition bonds into perpetuity.
} 
return under the previous system, $G$. In effect, the government calculated the bond as $\hat{B}_{2}^{j}=\tau \alpha_{1}^{j} w l_{1}^{j} R$, which is more-than actuarially fair when $R>G$ since $\hat{B}_{2}^{j}>B_{2}^{j}$.

The difference, $\hat{B}_{2}^{j}-B_{2}^{j}$, represents a windfall to second-period households that had to be financed with distorting labor income taxes. As will be clear from the analysis presented in the next section, this windfall effectively increases the value of accrued benefits and, therefore, works exactly in the opposite direction that is needed to reduce labor supply distortions. In the current model, therefore, the Chilean reform produced a Pareto inferior outcome. Of course, in reality, the Chilean reform potentially had many political-economy outcomes that are not captured in the standard model herein.

In contrast, the President's Commission to Strengthen Social Security proposed two plans that included voluntary "carve outs" that were more-than actuarially fair in the sense that these plans proposed reducing the present value of future Social Security benefits by less than the amount of dollars that workers carve out into their own personal accounts. This windfall is intended to entice workers to choose the accounts. Unlike the overpayment in the case of recognition bonds, however, it is easy to show that this "windfall" is not a source of inefficiency since it is only applied to new contributions. On one hand, this subsidy reduces the effective tax rate on contributions. On the other hand, the windfall must be financed with new distorting pure taxes. The net effect is a wash.

\section{REDUCing LABOR MARKET Distortions}

This section shows how privatization can be structured in way that reduces labor supply distortions and potentially produces a Pareto gain.

\subsection{Privatization with Limited Transition Relief}

Consider the following privatization plan: 
- Retirees at time of reform get paid benefits under current law.

- Workers in the second period at the time of the reform lose their accrued benefits, which has a value equal to $B_{2}^{j}$ during the second period. In exchange, their labor taxes are reduced the same amount in present value. These two steps can be accomplished in at least two different ways (or a combination of both):

○ An "accrued carve out": Decrease the traditional benefits received the following period by $R B_{2}^{j}$ and decrease traditional second-period payroll taxes by the amount of benefits previously accrued, $B_{2}^{j}$.

○ A "shut down" without recognition bonds: Eliminate social security benefits and collect $\tilde{T}_{2}^{j}-B_{2}^{j}$ in taxes during the second period to help service the benefits paid to initial retirees.

- First-period workers and all future generations pay nothing into social security and receive no benefits. Instead, they pay a pure tax $\tilde{T}_{1}^{j}$ during the first period of life and $\tilde{T}_{2}^{j}$ during the second period of life to help service the benefits paid to initial retirees.

Notice that taxes do not go to zero even in the long run under this policy change because benefits must still be paid to retirees at the time of the reform; these tax payments are of equal value in present value. ${ }^{13}$ However, the accrued benefits owed to second period workers alive at the time of the reform do not have to be paid. As shown below, this lump-sum wealth levy is a source of efficiency gains.

\footnotetext{
${ }^{13}$ In practice, the government would issue debt to finance the benefits of the initial retirees. In this case, the tax payments on subsequent generations in the text would exactly service the debt into perpetuity.
} 


\subsection{Efficiency Gains}

This privatization plan holds harmless the retirees at the time of the reform. Young and future workers are also directly held harmless since they face the same effective budget constraints after privatization, $\left(1^{\prime}\right)-\left(3^{\prime}\right)$, as they did before the reform, (1) - (4). We show below, however, that future workers gain indirectly from this privatization plan due to improvements in the government's budget constraint.

\subsubsection{Middle-Aged Workers}

Any direct reductions in labor supply distortions, therefore, must stem from second-period workers alive when privatization is introduced who accrued benefits under the former social security system. We now demonstrate these gains.

Recall, that as shown in Section 3, agent $j$ in their second period of life when privatization is introduced is indifferent between the initial social security system, shown in constraints (1) - (4), versus a privatized system where he or she receives their accrued liability, $B_{2}^{j}$, and where they pay the tax labor tax, $\tilde{T}_{2}^{j}$, as shown in constraints (17) (19). That was the reason the actuarially-fair shutdown discussed in Section 3 is neutral.

In the privatization plan just outlined above, however, the accrued benefit, $B_{2}^{j}$, is "defaulted" upon, i.e., not paid. Instead the pure tax, $\tilde{T}_{2}^{j}$, paid during the second period is lowered by the amount, $B_{2}^{j}$. Specifically, the proportional pure tax rate paid on secondperiod labor income decreases from $[1-(G / R)] \tau$ shown in equation (6) to $[1-(G / R)] \tau-\frac{B_{2}^{j}}{\alpha_{2}^{j} w(1+x) l_{2}^{j^{*}}}$, where $\alpha_{2}^{j} w(1+x) l_{2}^{j^{*}}$ is the deterministic amount of second-period labor income (observable to the government in the second best setting) 
before privatization. ${ }^{14}$ Since this tax reduction is "compensated" with an implicit levy on accrued benefits, it follows that agent $j$ supplies more labor and achieves more utility.

These results are illustrated in Figure 1. The level of leisure is shown on the vertical axis while the present value of remaining consumption is on the horizontal axis. The line $\mathrm{A}-\mathrm{X}$ corresponds to the original budget constraint under the original social security program where a second-period agent faces the tax rate $[1-(G / R)] \tau$ on labor income during the second period of life and has accrued a social security benefit of $B_{2}^{j}$ and private savings, $a_{1}$. The optimal choice between leisure and consumption is point $O$.

Figure 1

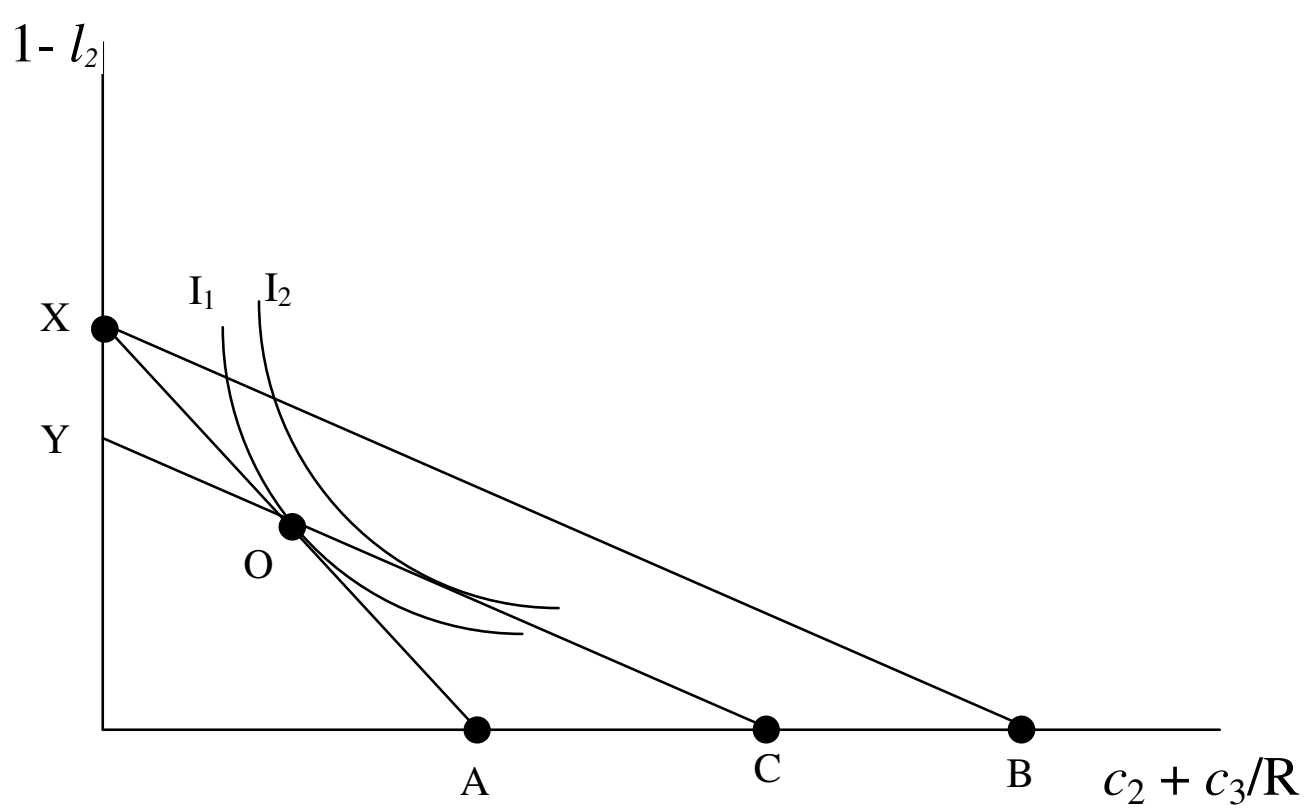

Privatization produces two effects. First, the reduction in the proportional labor income tax rate creates a new budget set $\mathrm{B}-\mathrm{X}$ in Figure 1 as the relative price of consumption decreases, increasing the maximum amount of consumption from Point A to

\footnotetext{
${ }^{14}$ The new tax rate comes from solving $\hat{\tau} \alpha_{2}^{j} w(1+x) l_{2}^{j}=\tilde{T}_{2}^{j}-B_{2}^{j}$ for $\hat{\tau}$.
} 
B. Second, the loss in the accrued benefit $B_{2}^{j}$ shifts the budget constraint $\mathrm{B}-\mathrm{X}$ downward to $\mathrm{C}-\mathrm{Y}$. Line $\mathrm{C}-\mathrm{Y}$ intersects with the original budget constraint $\mathrm{A}-\mathrm{X}$ at the original optimum, $O$, since agent $j$ can still afford the optimal bundle of consumption and leisure before privatization. However, the new budget constraint $\mathrm{C}-\mathrm{Y}$ affords a higher level of utility, as shown by the outward shift of the indifference curve from $I_{1}$ to $I_{2}$.

Notice that agent $j$ also supplies more labor. The government's budget constraint, therefore, also improves by this policy change since more revenue is collected from the taxes that remain on the second-period workers. In general equilibrium, therefore, young and future workers also gain indirectly from privatization since their tax rates must be lowered in order to satisfy the government's inter-temporal budget constraint, (11). ${ }^{15}$

Proposition 3. Privatization with limited transition relief, as outlined above, increases the utility of current and future workers without decreasing the utility of current retirees, i.e., a Pareto improvement even with second-best labor income taxes.

\subsection{Implementation Issues}

A few practical issues emerge in the implementation of privatization. First, notice that the financial institution of "personal accounts" is not explicitly modeled. The reason is that agents are rational in the current model and so they don't need to be told to save. Suppose, though, that policymakers believe that households' place a weight on future utility, $\beta$, that is "too low," thereby generating too little saving after reform. ${ }^{16}$ To address this problem, the contribution rate in the new system could be set at the same rate as

\footnotetext{
${ }^{15}$ Of course, these gains could also be shared with current retirees by increasing their benefits.

${ }^{16}$ This behavior could be irrational (i.e., myopia) or rational (i.e., the Samaritan's dilemma / moral hazard).
} 
under the pre-reform program; the difference between the new contribution rate and the new pure taxes that are needed to service the benefits of the initial retirees would then be deposited into mandatory personal accounts. The efficiency gains derived earlier would still materialize because second-period workers would get a higher rate of return on their contributions into personal accounts when the economy is dynamically efficient $(R>G)$.

Second, notice that the net taxes for young and future workers in the new system decrease by age, $\tilde{\tau}_{2}^{j}<\tilde{\tau}_{1}^{j}$. As shown in Section 2, effective tax rates also decrease in the traditional system; the pure tax rates simply become more explicit in the new system. In practice, however, if the personal accounts were mandatory (for reasons just discussed), the pure taxes could be implemented indirectly by depositing less into personal accounts for young workers relative to older workers with the same labor income.

Third, the new pure tax rate on some second-period households alive immediately after privatization could go negative (a wage subsidy), especially for those households that accumulated enough benefits under social security. ${ }^{17}$ A negative wage tax, though, is not itself a problem: a wage subsidy will also produce a higher level of labor supply and utility, as shown in Figure 1, if it is financed with a reduction in accrued benefits. If contributions to personal accounts were mandatory, this subsidy could take the form of a government match of personal contributions that is phased out over time. Alternatively, the government could instead set tax rates to zero and give the household the remainder as a partial recognition bond. But, relative to the contribution match, this bond would reduce the implicit lump-sum tax on accrued assets, thereby mitigating some of the gains.

${ }^{17}$ I.e., $[1-(G / R)] \tau-\frac{B_{2}^{j}}{\alpha_{2}^{j} w(1+x) l_{2}^{j^{*}}}$ is negative if $B_{2}^{j}$ is sufficiently large. 
Fourth, in the few countries where social security benefits are progressive (e.g., the United States), the accrued value of social security benefits at the time of the reform also depend on future labor income. In the deterministic second-best setting herein, the government can forecast future labor income (although not wages) with perfect foresight, and so incorporating a progressive benefit schedule is not a problem. In the presence of wage and longevity uncertainty, though, a reasonable projection would have to be made. But the incorporation of uncertainty leads to several risk sharing issues that require the use of simulation analysis to determine efficiency gains (Nishiyama and Smetters, 2004). The current paper simply focuses on demonstrating the source of potential gains from privatization in the second-best setting, which not well understood in the literature.

\subsection{A Back-of-the Envelope Calculation}

It is interesting to get a sense of the potential gains from privatization. In the U.S. Social Security system, the value of accrued liabilities for current participants is to equal about $\$ 12$ trillion. About $\$ 3$ trillion worth belong to retirees no longer in the labor force. That leaves about $\$ 9$ trillion available for reductions in labor supply distortions.

Somewhat, conservatively, suppose that workers above age about 55 were exempt from reform and so only about $\$ 5$ trillion of accrued benefits would be subject to a wealth levy. If the excess burden of the U.S. payroll were about $20 \%$ (consistent with estimates in Feldstein, 1996), then privatization could induce about $\$ 1000$ billion in efficiency gains. ${ }^{18}$ Recent estimates by Prescott (2004) of the labor supply elasticity suggest that even larger marginal excess burdens are possible.

\footnotetext{
${ }^{18}$ For the U.S. system, Feldstein (1996) estimates the excess burden equal to 2.35 percent of the payroll tax base, or about $20 \%$ of the payroll tax revenue. In that same article, he estimates even larger gains from privatization relative to first-best taxes.
} 
These calculations, though, should be interpreted with caution. For example, they ignore the administrative costs of personal accounts relative to social security (Diamond, 1996). They also ignore how a social security system shares various types of risk over the lifecycle that might be hard to insure in the private sector (Diamond, 1977).

\subsection{Comparison with the Standard "Carve Out" and "Shutdown"}

It is now quite straightforward to see that the reason that the standard "carve out" and "shutdown" privatizations considered earlier failed to produce efficiency gains is that neither approach imposes an implicit lump-sum levy on accrued liabilities. The "carve out" implicitly preserves accrued liabilities by only reducing benefits made on new contributions; the "shut down" explicitly preserves accrued liabilities with recognition bonds. Ironically, attempting to provide relief to workers in the transition actually undermines the potential source of efficiency gains. In the case of Chile and some other countries, these workers were actually over protected, which induced losses.

\subsection{Can the Same Efficiency Gains be achieved with Other Reforms?}

The privatization with limited transition relief considered in Section 4 imposes an implicit lump-sum wealth levy that is used to reduce future distorting taxes. This policy change is similar in spirit to replacing a wage tax with a consumption tax: a consumption tax is equivalent to a wage tax plus a lump-sum tax on existing assets.

A legitimate question, therefore, is whether the same efficiency gains derived herein could be obtained by simply adopting a consumption tax. The answer is no. The switch to a consumption tax redistributes resources across generations by implicitly imposing a lump-sum tax on non-social security wealth held by households alive at the time of the reform, thereby reducing the tax rates on subsequent generations. Accrued 
social security wealth in many countries, including the U.S., would not be taxed because benefits are protected in real after-tax terms (including price increases due to a retail sales tax or a value-added tax). Moreover, even if inflation protection rules were removed, a consumption tax could not isolate the benefits accrued under social security and, therefore, could not confiscate them altogether in a revenue-neutral fashion. Hence, some efficiency gains would still remain. Finally, as a practical matter, protecting retirees from the losses of a consumption tax requires detailed transition rules; in contrast, the privatization herein avoids negative inter-generational transfers.

A related question is whether the same gains from privatization could be achieved within the traditional social security system. Suppose, for example, the government effectively defaulted on accrued benefits and reduced payroll taxes. That approach, though, would be no different than the privatized experiment considered earlier. Instead, therefore, the government would have to default on accrued benefits and used this implicit lump-sum tax to produce a larger internal rate of return on future contributions for current workers without lowering tax rates. With this approach, though, younger workers would continue to accrue benefits under the traditional social security system and so, in a dynamic context, they should expect future wealth levies as well, which produces a new set of marginal tax rates. In contrast, the wealth levy on accrued benefits in the privatization experiment considered herein can be done only once because the social security system is eventually abandoned. Instead, future wealth levies would require a new tax on the assets in the private accounts, which might be more difficult. 


\section{ConClusions}

It is generally believed that privatization of social security does not produce efficiency gains when the government's tax instruments are second best. Much of this conventional wisdom, though, has been developed within the standard two-period lifecycle model where agents work the first period and retire the second period. In this context, privatization simply swaps one distorting tax for another.

This paper demonstrates that a Pareto improvement is possible in a lifecycle model with three or more periods where older workers have accrued benefits under the traditional system. Accrued benefits become a source for an efficient wealth levy used to afford a larger (capital market) rate of return on future contributions, thereby reducing the effective tax rate on labor at the margin. A back-of-the-envelope calculation suggests that the efficiency gains for the U.S. could exceed $\$ 1$ trillion, although, as explained in Section 4 , this calculation should be interpreted with some caution. 


\section{REFERENCES}

Abel, Andrew B., N. Gregory Mankiw, Lawrence H. Summers, and Richard J. Zeckhauser, "Assessing Dynamic Efficiency: Theory and Evidence," Review of Economic Studies 56 (January 1989): 1-20.

Auerbach, Alan and Laurence Kotlikoff, Dynamic Fiscal Policy, Cambridge University Press, 1987.

Breyer, F. "On the Intergenerational Pareto Efficiency on Pay-as-you-go Financed Pension Systems." Journal of Institutional and Theoretical Economics, 1989, 145: 64358.

Breyer, F. and M. Straub. "Welfare effects of unfunded pension systems when labor supply is endogenous," Journal of Public Economics, 1993, 50: 77-91.

Bohn, Henning. "Intergenerational Risk Sharing and Fiscal Policy." Mimeo, UC Santa Barbara, 2003.

Brunner, Johann. "Transition from a Pay-as-you-go to a Fully Funded Pension System: The Case of Differing Individuals and Intragenerational Fairness." Journal of Public Economics, 1996 (60): 131 - 146.

Diamond, Peter. "A framework for Social Security Analysis," Journal of Public Economics, 1977, 8: 275-298.

Diamond, Peter. "Proposals to Restructure Social Security," Journal of Economic Perspectives, 1996, 10 (3): 67-88.

Diamond, Peter and John Geanakoplos. "Social Security Investment in Equities." American Economic Review, vol. 93, no. 4, September 2003, pp. 1047-74.

Feldstein, Martin and Andrew Samwick. "Social Security Rules and Marginal Tax Rates." National Tax Journal, 45 (1), 1992: 1 - 22.

Feldstein, Martin. “Would Privatizing Social Security Raise Economic Welfare?" NBER Working Paper \#5281, 1995.

Feldstein, Martin. "The Missing Piece in Policy Analysis: Social Security Reform." The Richard T. Ely Lecture, in American Economic Review, 86, No.2, May 1996: 1 - 14.

Feldstein, Martin and Jeffrey Liebman, "Social Security." in Alan J. Auerbach and Martin Feldstein, editors, Handbook of Public Economics, volume 4, (Amsterdam: Elsevier), 2002. 
Geanakoplos, John, Olivia S. Mitchell and Stephen P. Zeldes, "Would a Privatized Social Security System Really Pay a Higher Rate of Return?" In Framing the Social Security Debate: Values, Politics and Economics. Eds. D. Arnold, M. Graetz, and A. Munnell. Brookings Institution, 1998: 137-157.

Gustman, Alan L; Steinmeier, Thomas L. "How Effective Is Redistribution under the Social Security Benefit Formula?" Journal of Public Economics, vol. 82, no. 1, October 2001, pp. 1-28

Krueger, Dirk and Felix Kubler. "Intergenerational Risk Sharing via Social Security when Markets are Incomplete" American Economic Review, 2002, Vol. 92(2), 407 - 410.

Laitner, John. "Social Security Reform and National Wealth." Scandinavian Journal of Economics, 102 (3), 2000: 349 - 371.

Mariger, Randall P. "Social Security Privatization: What Are the Issues?" National Tax Journal, vol. 52, no. 4, December 1999, pp. 783-802

Murphy, Kevin and Finis Welch, "Perspectives on the Social Security Crisis and Proposed Solutions," American Economic Review, 1998, 88: 142 - 150.

Nishiyama, Shinichi and Kent Smetters. "Does Social Security Privatization Produce Efficiency Gains?" Mimeo, CBO and The Wharton School.

Prescott, Edward. "Why Do Americans Work More than Europeans?" Federal Reserve Bank of Minneapolis Quarterly Review, vol. 28, no. 1, July 2004: 2-13

Samuelson, Paul. "An exact consumption-loan model of interest with or without the social contrivance of money" Journal of Political Economy, 1958.

Shiller, Robert. "Social Security and Institutions for Intergenerational, Intragenerational and International Risk Sharing." Carnegie-Rochester Conference Series on Public Policy, 1999, 50, 165-204. 